\title{
Can nurses legally perform surgical induced abortion?
}

\author{
Vincent Argent, Lin Pavey
}

\section{Introduction}

Many organisations have called for improved abortion services. ${ }^{1}$ The direct involvement of nurses in surgical abortions would be beneficial. ${ }^{2}$ It is our contention that English law allows registered nurses to perform surgical termination of pregnancy.

Current abortion law depends on the Abortion Act $1967,{ }^{3}$ as amended by the Human Fertilisation and Embryology Act 1990. Illegal abortion remains a criminal offence under the Offences Against the Person Act 1861. The Abortion Act 1967 states the conditions whereby legal abortion may be performed. Section 1(1) of the Act currently provides that:

"Subject to the provisions of this section, a person shall not be guilty of an offence under the law relating to abortion when a pregnancy is terminated by a registered medical practitioner...".

The interpretation and application of the Statute law has also been laid down in case law with authoritative precedent in the Court of Appeal and House of Lords.

In Royal College of Nursing of the United Kingdom $v$ Department of Health and Social Security (RCN v DHSS) (1981) the House of Lords considered the involvement of nurses in induced abortion and interpreted the meaning of Section 1(1). ${ }^{4}$

This case involved a 'medical' abortion and most people appear to believe that the judgement allows nurses to do medical abortions but not surgical abortions as, for example, the advice in the recently published Syllabus and Logbook for the Certificate in Abortion Care of the Faculty of Family Planning and Reproductive Health Care of the Royal College of Obstetricians and Gynaecologists. 5 This introduces eight competence-based blocks that cover the outpatient consultation and the various methods of abortion up to 24 weeks. All the blocks, including surgical procedures, are open to doctors but the Faculty states that only the three blocks on consultation and medical abortion are open to nurses and midwives. The Faculty cites the $R C N v$ DHSS case, stating: ${ }^{4}$

"By current law, nurses and midwives are unable to perform abortion procedures but can provide the medication prescribed by the doctors for medical abortions and assist in the provision of surgical procedures".

Our analysis of the Abortion Act 1967 and the RCN v DHSS case shows that registered nurses and midwives

J Fam Plann Reprod Health Care 2007; 33(2): 79-82

(Accepted 4 February 2007)

\section{Addenbrooke's Cambridge University Teaching Hospital, Cambridge, UK \\ Vincent Argent, FRCOG, LLB, Consultant Obstetrician and Gynaecologist (Lead in Sexual Health)}

Shoreham-by-Sea, UK

Lin Pavey, RGN, Member of RCN Nurses Working in Termination of Pregnancy Network

Correspondence to: Mr Vincent Argent, Department of Obstetrics and Gynaecology, Addenbrooke's Cambridge University Teaching Hospital, Hills Road, Cambridge CB2 OQQ, UK. E-mail: Vargent1@aol.com could currently perform surgical abortions themselves as long as a medical practitioner is in overall charge, even if the medical practitioner is not physically present.

\section{The case law: RCN v DHSS}

We consider some of the speeches made by the Law Lords in deciding this case and how they interpreted the Abortion Act 1967.

One of the Law Lords involved, Lord Diplock, commented that the Abortion Act 1967:

"... lacks that style and consistency of draftmanship both internal to the Act itself and in relation to other statutes which one would expect to find in legislation that had its origin in the office of parliamentary counsel".

The background to the case is given in Box 1. A close examination of the words used by their Lordships suggests that the judgement may allow registered nurses to perform surgical abortions as long as there is overall supervision by a registered medical practitioner.

\section{The Lords' speeches \\ Lord Wilberforce}

Lord Wilberforce was one of the two minority dissenters in the case but his speech described the clinical procedure (Box 2). This method of termination, extra-amniotic infusion of prostaglandins (EAPG ) via a catheter, was used for mid-trimester-induced abortions and has been largely superseded by either mifepristone and misoprostol use or the dilatation and evacuation operation.

Lord Wilberforce posed the question: "Has the pregnancy been terminated by the doctor; or has it been terminated by the nurse; or has it been terminated by doctor and nurse?". His final judgement was inconclusive.

\section{Is the procedure 'medical' or 'surgical'?}

The difference between medical and surgical procedures is fundamental to the question of whether nurses may perform surgical induced abortion.

Lawyers tend to use the term 'medical procedure' to cover a clinical procedure whether it is surgical or not surgical. Clinicians may also use the term 'medical' more generally but are more likely to distinguish the terms 'medical' and 'surgical' to differentiate between procedures.

\section{Box 1: Background to the case RCN v DHSS}

In 1981, the Royal College of Nursing (RCN) were concerned that the involvement of registered nurses in termination of pregnancy, by extra-amniotic drug infusion, might be illegal, and therefore a criminal offence, under the Abortion Act 1967.

The RCN specifically sought a declaration to the effect that the advice in a departmental circular [CMO (80)(2)] was wrong in law. This stated that, irrespective of the precise action taken, an abortion was legal provided that it was initiated by and was the responsibility of a registered medical practitioner. The RCN maintained that administering drugs through an extra-amniotic catheter meant that the nurse was terminating a pregnancy and therefore could be liable for performing an illegal abortion; the RCN questioned whether the nurse was entitled to the protection of the 1967 Act.

The RCN took legal action, and eventually the Department of Health and Social Security (DHSS) won the case by a three to two majority decision in the House of Lords. 
The first part of the EAPG procedure is invasive but does not involve any cutting or rupturing of the membranes. It may be considered that the first act of abortion is the instillation of the drugs via the catheter. Is this medical or surgical? The last part where the nurse gowned, gloved and masked - assists the passage of the fetus and the placenta has the appearance of a surgical procedure similar to delivery by a midwife.

There is no recognised standard definition of what constitutes a surgical procedure. The Royal Colleges and the medical defence societies give no strict definitions and there are clearly problems with defining some procedures. The term 'invasive' is of little use in making the distinction because even internal examinations such as rectal and vaginal examination may be considered invasive per se. Sometimes questions are raised over whether such procedures as depot injections, insertion of contraceptive implants, insertion of intrauterine contraceptive devices and colposcopic examination (without biopsy) and other endoscopic examinations are surgical or not. Clearly many interventional and surgical procedures do not require cutting with a scalpel. The difference between surgical and medical procedures at the interface remains unclear.

Lord Wilberforce showed this ambiguity where in Statement 9 of his description of the procedure, he stated: "after which the operation is considered to have failed". The general public and the clinical professions would generally regard use of the word 'operation' as meaning a surgical and/or invasive procedure.

\section{Lord Diplock}

Lord Diplock was of the opinion that the doctor is in overall charge even if the nurse performs the procedure and that this satisfies the terms of the Abortion Act 1967. He pointed out that the policy of the Act was to:

- broaden the grounds on which abortions may be lawfully obtained and

- ensure that the abortion is carried out with all proper skill and in hygienic conditions.

He concluded that the subsection "if two registered medical practitioners are of the opinion ...", etc. defines the circumstances which qualify a woman to have pregnancy terminated lawfully.

He also drew attention to the requirement in Subsection (3) that, except in cases of dire emergency, the treatment must be carried out in a National Health Service hospital (or private clinic specifically approved for that purpose by the minister). He said:

"It is in my view evident that, in providing that treatment for termination of pregnancies should take place in ordinary hospitals, Parliament contemplated that (conscientious objections apart) like other hospital treatment, it would be undertaken as a team effort".

And that:

"... acting on the instructions of the doctor in charge of treatment, junior doctors, nurses, paramedical and other members of the hospital staff would each do those things forming part of the whole treatment which it would be in accordance with accepted medical practice to entrust to a member of the staff possessed of their respective qualifications and experience".

Lord Diplock concluded that the Act appears to contemplate treatment that is in the nature of a team effort and to extend its protection to all those who play a part in it. The exoneration from guilt is not confined to the registered medical practitioner by whom a pregnancy is

\section{Box 2: Lord Wilberforce's description of the procedure}

There is an agreed statement as to the nature of this treatment and the part in it played by the doctors and the nurses or midwives. Naturally, this may vary somewhat from hospital to hospital but, for the purpose of the present proceedings, the assumption has to be made of maximum nurse participation (i.e. that the nurse does everything which the doctor is not required to do). If that is not illegal, participation of a lesser degree must be permissible.

1 The first step is for a thin catheter to be inserted via the cervix into the womb so as to derive, or create, a space between the wall of the womb and the amniotic sac containing the fetus. This is necessarily done by a doctor. It may, sometimes, of itself bring on an abortion, in which case no problem arises: the pregnancy will have been terminated by the doctor. If it does not, all subsequent steps are as follows:

2 The catheter (i.e. the end emerging from the vagina) is attached, probably via another tube, to a pump or a gravity feed apparatus. The function of the pump or apparatus is to propel or feed the prostaglandin through the catheter into the womb. The necessary prostaglandin is provided and put into the apparatus.

3 *The pump is switched on, or the drip valve is turned, thus causing the prostaglandin to enter the womb.

4 The doctor inserts a cannula into a vein.

5 *An oxytocin drip feed is linked up with the cannula. The necessary oxytocin (a drug designed to help the contractions) is supplied for the feed.

6 The patient's vital signs are monitored: so is the rate of drip or flow.

7 *The flow rates of both infusions are, as necessary, adjusted.

8 *Fresh supplies of both infusions are added as necessary.

9 The treatment is discontinued after discharge of the fetus, or expiry of a fixed period (normally 30 hours) after which the operation is considered to have failed.

10 The only steps in this process which can be considered to have a direct effect leading to abortion (abortifacient steps) are those asterisked. They are all carried out by the nurse or midwife. As the agreed statement records "the causative factor in inducing ... the termination of pregnancy is the effect of the administration of prostaglandin and/or oxytocin and not any mechanical effect from the insertion of the catheter or cannula".

All the above Steps 2 to 9 are carried out in accordance with the doctor's instructions, which should, as regards important matters, be in writing. The doctor will, moreover, be on call, but may in fact never be called.

terminated; it extends to any person who takes part in the treatment for its termination. He said:

"... the doctor need not do everything with his own hands; the requirements of the subsection are satisfied when the treatment for termination of pregnancy is one prescribed by a registered medical practitioner carried out in accordance with his directions and of which a registered medical practitioner remains in charge throughout".

\section{Prevention of mischief}

The 'Mischief Rule' is used to interpret statutory law. The courts can take into account the reasons why the legislation was passed; what mischief the legislation was designed to prevent?

Lord Diplock concluded that one of the purposes of the Act was to ensure that abortion is carried out with proper skill and hygienic conditions. Skilled nurses, performing surgical procedures in hygienic conditions on patients judged eligible under the grounds for abortion, are fulfilling the purpose of the legislation by avoiding unsafe abortions.

The other legal mischief to be prevented by the Abortion Act 1967 was illegal abortion. Illegal abortion is 
governed by the Offences Against the Person Act 1861 . Sections 58 and 59 of this Act describe "any poison or other noxious thing, or shall unlawfully use any instrument or other means whatsoever" as used by the woman herself or any other person. There is no distinction between medical and surgical procedures in the wording.

If there is no distinction in the original Act which describes the legal mischief, then it would appear reasonable to give a wide interpretation to the subsequent $R C N \vee D H S S$ judgement on the Abortion Act 1967 so that the nurse is protected whatever means she uses under the overall control of a registered medical practitioner.

\section{The two signatures}

Lord Diplock notes that the condition precedent for legal abortion is the requirement "two registered medical practitioners are of the opinion ...".

The well-respected barrister and consultant gynaecologist, Margaret Puxon, was also of the opinion that the presence of two doctors' signatures was the only deed necessary to satisfy the terms of the Abortion Act 1967 and make the abortion lawful. ${ }^{6}$

It could be said that any abortion, medical or surgical, performed by a nurse would be legal if it was undertaken after obtaining the two doctors' signatures.

\section{The team effort}

The nurse would be further protected by Diplock's view that abortion "would be undertaken as a team effort" where a nurse acts on the instructions of a doctor. He considered that each member of staff would do parts of the treatment according to accepted medical practice and depending on their qualifications and experience. He summarises that the doctor does not need to do everything with his own hands. He makes no distinction between surgical and medical procedures.

\section{Possessed of experience and qualifications}

In 1981, over 25 years ago, the boundaries between medical and nursing practice were quite strict and inflexible and few nurses carried out invasive procedures normally within the province of the medical profession. Diplock viewed treatment by nurses as:

"carrying out such parts of the treatment as in accordance with accepted medical practice are carried out by nurses or other members of the hospital staff without medical qualification".

In current practice, nurses have considerably extended the scope of their practice and it is accepted that they carry out treatment which they would not have been allowed to do a quarter of a century ago. Especially in gynaecology practice, there are nurses who perform procedures such as colposcopy, hysteroscopy, assisted conception egg collection and minor operations. This sphere of practice is carefully overseen by the Royal College of Nursing (RCN) and the Nursing Midwifery Council (NMC).

\section{Evidence for safe practice}

Trained nurses can provide a competent, safe surgical abortion service. A recent article and editorial in The Lancet $^{6}$ reported on the relative safety of first-trimester manual vacuum aspiration done by doctors and 'mid-level' providers (i.e. nurses, midwives and physician assistants) in South Africa and Vietnam. The randomised controlled trial demonstrated that with appropriate training, mid-level health care providers can provide first-trimester manual vacuum aspiration abortions as safely as doctors can.

Moreover, in the developed West, physician assistants have been providing abortion services legally in Vermont, USA since 1975 and two studies ${ }^{8,9}$ have shown that these practitioners provided abortions as safely as did doctors.

The safety question is very important as this satisfies the legal mischief rule interpretation of the Abortion Act 1967.

\section{Lord Roskill}

This Law Lord went further in concluding that the doctor does not actually need to be present during the abortion. He talks about treatment, making no distinction between medical and surgical procedures:

"My Lords, I read and reread the 1967 Act to see if I can discern in its provision any consistent pattern in the use of the phrase 'a pregnancy is terminated' or 'termination of a pregnancy' on the one hand and 'treatment for the termination of a pregnancy' on the other hand. I think one is reading 'termination of pregnancy' and 'treatment for the termination of pregnancy' as virtually synonymous and as I think Parliament must have intended they should read.

Such a construction avoids a number of anomalies as, for example, where there is no pregnancy or where the extra-amniotic process fails to achieve its objective within the normal limits of time set for its operation.

I think that the successive steps taken by a nurse in carrying out the extra-amniotic process are fully protected provided that the entirety of the treatment for the termination of the pregnancy and her participation in it is at all times under the control of the doctor, even though the doctor is not present throughout the entirety of the treatment."

\section{Wide interpretation and the doctor's presence}

Lord Roskill also emphasised the team system and considered that the Abortion Act 1967 should be widely interpreted to include procedures done by nurses under the overall supervision of doctors and in accordance with ordinary current practice. His use of the word 'current' allows an analysis of what nurses are able to do in current modern practice and a comparison with the practices back in 1981. This would allow acceptance of the current and developing wide involvement of nurse practitioners in surgical and invasive procedures.

He also uses the terms 'process' and 'operation' for extra-amniotic termination of pregnancy and makes no distinction between surgical and medical procedures.

Most importantly, Lord Roskill considers that the nurse is entitled to the protection of the Abortion Act 1967 where she participates in a process that is at all times under the control of a doctor even though the doctor is not present throughout the entirety of the procedure. Surgical termination can be considered as a process under the doctor's control even if he is never actually present. The two other judges, one dissenting and the other allowing the appeal, did not add any further main points.

\section{Discussion of the RCN case by legal authorities}

What do the leading texts on medical law say about the case of RCN $v$ DHSS?

Kennedy and Grubb ${ }^{10}$ consider that the case effectively settles questions about the involvement of members of a team who are not registered medical practitioners.

They make no distinction between surgical and medical procedures. They do have concern about the current widespread practice of medical abortion by mifepristone followed by prostaglandins. The mifepristone is prescribed 
by a doctor, dispensed by a pharmacist and taken by the woman herself in the presence of a nurse. This begs the question as to who actually terminates the pregnancy. The authors are not sure whether this procedure is protected, as it is a different kind of responsibility from the RCN case. They conclude, however, that any future court case would give a wider interpretation to the Abortion Act 1967 to cover the administration of mifepristone by nurses. The use of mifepristone and misoprostol by nurses is well established in current practice and there has been no attempt to challenge this under the Act.

It could therefore be considered that any future case involving nurses performing surgical abortion under the overall supervision of a medical practitioner as part of the team would also give protection under the Abortion Act 1967.

Mason and McCall Smith ${ }^{11}$ note that the role of nurses in therapy is becoming more significant. They are of the opinion that the RCN case protects nurses, adding that:

"effectively, therefore, abortion, no matter how it is performed, is a team effort and is no different in this respect from any other form of treatment".

They also make no clear distinction between medical and surgical procedures.

Montgomery ${ }^{12}$ discusses how the Department of Health uses circulars offering explanation of legal requirements, which subsequently led to the RCN challenge in this case. He makes no distinction between medical and surgical techniques. In his analysis of the case, he states that:

"All that the Act requires is that the decision to terminate the pregnancy and the choice of the method to be used are made by a doctor who remains on call and responsible for the woman's treatment throughout the procedure ... A termination will be lawful under the 1861 Act even when carried out by a nurse, provided that a doctor remains responsible".

Dimond, in Legal Aspects of Nursing, ${ }^{13}$ writes that:

"The decision (in $R C N \vee D H S S$ ) has considerable significance for the scope of professional practice. It could be argued that even where a statute expressly places responsibility on a registered medical practitioner, the law is still followed when the activity is delegated to another health care professional acting under the aegis of the registered medical practitioner."

No distinction is made between medical and surgical procedures. Dimond notes that the ten key roles in The NHS Plan 14 include "to perform minor surgery" and adds that the scope of professional practice should be judged by the new Code of Professional practice drawn up by the NMC. Paragraph 6 of the Code requires practitioners to maintain their professional knowledge and competence. The book notes the intent of the NHS Plan to "shatter the boundaries" of unnecessary demarcations in health care provision.

McHale, Tingle and Penser also give an interpretation in the book Law and Nursing. 15 They state:

"As with other hospital treatment, abortion would take place as a team effort: junior doctors, nurses and other members of the health care team would each undertake those tasks which would be, in accordance with a responsible body of medical practice, entrusted to a member of staff possessed of their respective skills".

The involvement of the nurse in the process was lawful. They also make no distinction between medical and surgical procedures.

\section{Conclusions}

Close analysis of the wording and a wide interpretation of the Abortion Act 1967 should allow nurses to perform surgical abortions as part of a team effort as long as the whole process is under the control of a registered medical practitioner, even though the doctor is not present throughout the entirety of the procedure.

The RCN v DHSS case has been misinterpreted as only allowing nurses to undertake medical abortions. In reality, the Lords' judgements in the case made no distinction between surgical and medical procedures and gave no specific ruling that their conclusion would only apply to the method used in the case. They considered that nurses and doctors should act according to current accepted clinical practice. In current practice, nurses would possess the necessary experience and qualifications, as required by the judgement in the case, if they undertook the appropriate prescribed levels of training as laid down for Certificates 4-8 of the Faculty of Family Planning and Reproductive Health Care. The increasing development of nurses' skills should allow them to be trained to undertake surgical abortions under the protection of the Abortion Act 1967 and the true interpretation of the RCN $v$ DHSS ruling.

\section{Editor's note}

See also the Commentary article by Professor Gill Wakley on page 77 of this journal issue.

Statements on funding and competing interests

Funding Vincent Argent receives fee income for clinical sessional work at bpas.

Competing interests Lin Pavey is a member of the RCN Nurses Working in Termination of Pregnancy Network, however the opinions expressed in this article represent her own views.

\section{References}

1 Argent V. Abortion law: campaign groups and the quest for change. J Fam Plann Reprod Health Care 2006; 32: 215-217.

2 Argent V. How can abortion be made simpler for women? J Fam Plann Reprod Health Care 2006; 32: 67-69.

3 The Abortion Act 1967. London, UK: HMSO, 1967.

$4 R C N v$ DHSS [1981] 1 All ER 545.

5 Faculty of Family Planning and Reproductive Health Care. Syllabus and Logbook for the Certificate in Abortion Care of the Faculty of Family Planning and Reproductive Health Care of the Royal College of Obstetricians and Gynaecologists. http://ffprhc.org.uk/pdfs/AbortionCareLogbook.pdf [Accessed 2 February 2007]

6 Puxon M. Litigation in Obstetrics and Gynaecology. London, UK: Royal College of Obstetricians and Gynaecologists, 1985.

7 Warriner I, Merik O, Hoffman M, Morroni C, Harries J, My Huong $\mathrm{N}$, et al. Rates of complications in first-trimester manual vacuum aspiration abortion done by doctors and mid-level providers in South Africa and Vietnam: a randomised controlled equivalence trial. Lancet 2006; 368: 1965-1972.

8 Freedman $M$, Jillson D, Coffin R, Lloyd F. Comparison of complications rates in first trimester abortions performed by physician assistants and physicians. Am J Public Health 1986; 76: $550-554$.

9 Goldman M, Occhiuto J, Peterson L, Zapka J, Palmer R. Physician assistants as providers of surgically induced abortion services. Am J Public Health 2004; 94: 1352-1357.

10 Kennedy I, Grubb A. Medical Law. London, UK: Butterworths, 2000.

11 Mason J, McCall Smith R. Law and Medical Ethics. London, UK: Butterworths, 1999.

12 Montgomery J. Health Care Law. Oxford, UK: Oxford University Press, 2003

13 Dimond B. Legal Aspects of Nursing. Harlow, UK: Longman, 2004.

14 Department of Health. The NHS Plan: A Plan for Investment, $A$ Plan for Reform. London, UK: The Stationery Office, 2000.

15 McHale J, Tingle J, Penser J. Law and Nursing. Oxford, UK: Butterworth Heinemann, 1998. 